\title{
Revisitando Estudos Sobre a Inteligência Emocional no Âmbito do Secretariado Brasileiro
}

\section{Revisiting Studies on Emotional Intelligence in the Brazilian Secretarial Field}

Bianca Teixeira Nonato ${ }^{1}$ e Eduardo César Pereira Souza ${ }^{2}$

${ }^{1,2}$ Universidade Federal do Amapá, UNIFAP 


\title{
Resumo
}

A Inteligência Emocional (IE) tornou-se o “ingrediente” principal de diversos estudos das áreas de Psicologia, Administração, Medicina, Enfermagem, Direito, Educação Física, e, também, no campo do Secretariado, pela necessidade de os profissionais se enquadrarem nas exigências atuais das organizações como colaboradores inteligentes emocionalmente. A exigência por esse perfil profissional torna-se elemento motivador para a construção de um cenário que procure resolver dificuldades relacionadas ao trabalho sob pressão, cobrança por resultados cada vez mais rápidos, além de sobrecarga de atividades. Assim sendo, este trabalho objetivou realizar uma revisão bibliográfica sobre a IE no âmbito do secretariado. No que diz respeito aos aspectos metodológicos, trata-se de uma pesquisa descritiva, quanto ao objetivo, e bibliográfica, no que concerne à técnica empregada para coleta de dados. Como resultados, foi possível mapear trabalhos sobre a IE, no contexto secretarial, e descobrir que não é um tema tão novo como parece, já que o primeiro estudo sobre a temática, identificado no contexto deste trabalho, foi o de Mello (2005). Em contrapartida, o estudo permitiu descobrir que este tema tem se tornado cada vez mais frequente nos estudos da área secretarial, suscitando, desse modo, a importância de discussões contemporâneas sobre o assunto.

Palavras-chave: inteligência emocional, secretariado, revisão bibliográfica

\begin{abstract}
Emotional Intelligence, henceforth (EI), has become the main ingredient of several studies in the areas of Psychology, Administration, Medicine, Nursing, Law, Physical Education, and also in the Secretarial field, due to the need for professionals to fit into the current demands of organizations for emotionally intelligent employees. Some of the motivators for the construction of this scenario can be named as difficulties to work under pressure, demand for increasingly faster results, and work overload. Therefore, this work aims to perform a literature review on El in the secretarial field. Regarding the methodological aspects, this is a descriptive research with bibliographical the technique used for data collection. As results, it was possible to map works about El in the secretarial context and discover that it is not such a new theme as it seems, since the possible first study on the subject was by Mello (2005). On the other hand, the study allowed us to discover that this theme has become increasingly frequent in studies of the secretarial area, thus raising the importance of contemporary discussions on the subject.
\end{abstract}


A Inteligência Emocional (IE) pode ajudar no combate ao estresse provocado pela quantidade de trabalho nos escritórios, diminuindo o adoecimento psicológico advindo da pressão pelas demandas e obrigações enfrentadas nas rotinas dos profissionais de secretariado que não possuem capacidade para lidar com elas (Pereira et al., 2021). Assim sendo, a IE tem sido objeto de investigação de diferentes áreas como: Administração, Filosofia, Educação, Sociologia, Psicologia, dentre outras, a fim de se entender qual a importância dela, quais os tipos de comportamentos dos colaboradores dentro das organizações e como esses indivíduos irão atuar na facilitação e cooperação para a resolução dos conflitos que eventualmente possam surgir nas empresas.

Estudos realizados até a década de 1990 mostram que o Quociente Intelectual (QI) determinava o sucesso profissional de um indivíduo e, por isso, as organizações se baseavam nesses testes para identificar o QI de seus líderes e colaboradores. Com a evolução da ciência e da aplicação dos métodos coaching, assim como pesquisas nas áreas da Administração, Psicologia, Psiquiatria e, atualmente, da Neurociência, foi descobrindo-se que existiam diferentes fatores que determinavam o sucesso e os comportamentos das pessoas dentro das organizações, chegando ao que hoje conhecemos por Quociente Emocional (QE) (Costa, 2014).

O autocontrole das emoções pode trazer mudanças significativas, tanto no ambiente profissional quanto familiar e pessoal, uma vez que a pessoa se torna mais consciente de suas responsabilidades, usando as habilidades adquiridas e aprimoradas para promover uma mudança cultural e social no meio em que vive e/ou trabalha (Goleman, 2007). Fato que corrobora com as palavras de Goleman (1998, p. 14), "talvez minha maior surpresa tenha sido o impacto do QE no mundo dos negócios, principalmente nas áreas de liderança e desenvolvimento de funcionários - uma forma de educação para adultos".

Tendo em vista a introdução aqui apresentada, este estudo pretende realizar uma revisão bibliográfica sobre a IE no âmbito do secretariado brasileiro. Assim sendo, busca-se responder à seguinte questão-problema: uma vez que os estudos sobre IE não são recentes e, aparentemente, já há uma quantidade significativa de trabalhos sobre o assunto no secretariado, qual o panorama atual dessas pesquisas? Desse modo, entende-se que mapear as produções já publicadas sobre IE no secretariado será importante para conhecer o quanto já se evoluiu ou não na temática, do mesmo modo que sinalizar novas perspectivas de pesquisa para o campo.

Em resumo, o trabalho está estruturado da seguinte forma: inicia-se com esta introdução; em seguida, tem-se o referencial teórico, que aborda, na primeira parte, o tópico IE, com visão geral e, na segunda, a IE no secretariado. Depois, inserem-se os aspectos metodológicos do estudo, pospostos pela apresentação dos resultados e discussões. Por fim, apresentam-se as considerações finais da pesquisa e listam-se as referências utilizadas na produção do texto.

\section{Referencial Teórico}

\section{A inteligência emocional: compreendendo um conceito}

O conhecimento voltado à gestão e o controle dos processos emocionais e sentimentais, assim como a habilidade para compreender as atividades desenvolvidas por terceiros, é uma competência necessária no ambiente organizacional (Sprea, 2009). Além do conhecimento teórico-prático, o mercado de trabalho exige 
um conhecimento autônomo atrelado a outras características que demonstrem autonomia como a motivação, gerenciamento de habilidades sociais e empatia (Fonseca, Valle, Reis, \& Mesquita, 2016). Dessa forma, entende-se que não basta ter competência técnica, é necessário, também, possuir competências comportamentais, atitudinais, sociais.

Sabe-se que existem diversos conceitos para o termo IE, no entanto, por questões de recorte teórico, reproduz-se alguns deles a seguir:

Goleman (1995, p. 48):

A IE inclui características como a capacidade de motivar a si mesmo, de perseverar no empenho apesar das frustrações, de controlar os impulsos, de adiar as gratificações, de regular os próprios estados de ânimo, de evitar a interferência da angústia nas faculdades racionais, de sentir empatia, de confiar nos demais, etc. Como se pode ver na descrição de Goleman (1995), trata-se de um estado de autoconhecimento profundo e complexo. Evidentemente, ela não pode ser vista como algo fácil de se obter, já que envolve múltiplas áreas do viver pessoal e social. Em linhas gerais, a IE é um conjunto de fatores emocionais, pessoais e sociais que influenciam na habilidade adaptativa das pessoas frente às pressões e demandas do ambiente (Bar-On, 2000, 2006). Na visão de Mayer e Salovey (2007, p. 32):

A inteligência emocional implica a habilidade para perceber e valorar com exatidão a emoção; a habilidade para acessar e ou gerar sentimentos quando esses facilitam o pensamento; a habilidade para compreender a emoção e o conhecimento emocional, e a habilidade para regular as emoções que promovem o crescimento emocional e intelectual.

Em complemento, parece oportuno destacar que Fulanetto (2012, p. 17) afirma que a IE está profundamente associada às habilidades de uma pessoa, como a "automotivação e a persistência diante de dificuldades vividas; o autocontrole, expor as emoções de maneira apropriada e conseguir extrair do próximo o melhor de sua personalidade apenas com a empatia". Quer dizer, não se trata de uma competência passageira, mas de uma habilidade que possibilita a inserção nos diferentes espaços da vida cotidiana, a partir do uso da empatia, do saber se colocar no lugar do outro.

Lauer (2012, p. 103) também contribui na definição do termo IE. Para ele, ela deve ser considerada como "a capacidade de administrar as emoções para alcançar os objetivos". Segundo este autor, os indivíduos, quando entenderem do que se trata a IE, poderão encarar de forma mais eficaz suas insatisfações, emoções, medos e inseguranças, refletindo, dessa forma, em um ser humano bem-sucedido em suas jornadas diárias, pois é rotineiro uma pessoa agir por emoção.

A IE contém 5 (cinco) competências envolvendo a emoção e situações básicas sociais que são classificadas por Goleman (2001, p. 338) como: "autopercepção, auto-regulamentação, motivação, empatia e habilidades sociais". Nesse sentido, pensa-se que é possível benefícios para si e para outras pessoas, por meio de tais competências, desenvolver aptidões que parecem ser úteis em qualquer que seja a situação. A seguir, estão elencadas as principais aptidões: 
Figura 1

Principais aptidões adquiridas pela IE

Autoconsciência Emocional

Controle das Emoções

Canalizar Produtivamente as Emoções

Lidar com Relacionamentos

Empatia
Um melhor reconhecimento das próprias emoções, entendendo as causas desses sentimentos.

Desenvolver uma maior tolerância à frustração controlando a raiva de modo a diminuir possíveis comportamentos agressivos; aumentar o sentimento positivo sobre si mesmo; diminuir a solidão com menos ansiedade social.

Ser mais comunicativo e menos impulsivo, desenvolvendo o autocontrole.

Conseguir analisar melhor como ocorre cada relacionamento; procurar ser mais aberto e amistoso na forma de se relacionar com mais atenção e harmonia. Conseguir Visualizar como é importante a perspectiva do outro, melhorando a forma de ouvir e desenvolvendo a sensibilidade aos sentimentos do próximo.

Nota. Extraído de Goleman (1995, p. 302).

Conforme as informações supracitadas, é perceptível que a Inteligência Emocional irá preconizar o potencial do profissional para adquirir os fundamentos de autonomia do domínio, conhecimento e emocional, além de controle destes. A autonomia do controle, provenientes dos resultados daquele que faz uso da inteligência emocional, as críticas habituais e aos pensamentos próprios e paradigmas aumentam o período de reação prédeterminada, possibilitando ao profissional uma base na tomada de decisões, principalmente nos períodos constantes de estresse, em uma quantidade elevada de variáveis, ou seja, informações armazenadas na memória (Moreira, 2017).

A seguir, apresenta-se o segundo tópico deste referencial teórico sobre a IE no secretariado.

\section{A inteligência emocional no secretariado: contexto e perspectivas}

A profissão de secretariado executivo tem se adequado às mudanças impostas a ela ao longo do tempo e o profissional que desempenha esse ofício deve se adaptar ao novo perfil exigido pelo mercado de trabalho, as determinações da lei e do código de ética que regulamentam sua atuação (Alonso, 2002). Frente a esse cenário, o secretário executivo busca aprimoramento e ampliação de conhecimentos relacionados às suas atividades-típicas, afinal, trabalhar com pessoas não é algo simples. No entanto, precisa ser considerado o fato que cada indivíduo apresenta uma maneira de agir e características particulares para lidar com pressões diárias, sejam elas no trabalho ou fora dele (Pereira, Maciel, Clericuzi, \& Deus, 2019).

Como afirmado por Lourenço e Lelis (2019), aquele que exerce a profissão de secretário executivo no mercado de trabalho atual, campo essencialmente multidisciplinar, lida com um fluxo intenso de informações, além de cobranças da equipe, que podem causar um descontrole emocional. Essa realidade, por sua vez, pode levá-lo a um cansaço psicológico, afetando sua produtividade e a capacidade de um relacionamento harmonioso com a equipe e principalmente com profissionais hierarquicamente superiores, ambiente em que a demanda de atividades é intensa (Lourenço \& Lelis, 2019). 
Além da desenvoltura de funções voltadas à gestão secretarial, o secretário executivo deve ter uma visão que envolva estratégia, atuando em conjunto com o executivo, como assessor. Nonato Junior (2009, p. 32) destaca que "o aparato técnico, tático e estratégico do Secretariado Executivo se reformulou quase que inteiramente nas últimas três décadas, tornando-se cada vez mais próximo das novas tecnologias e das demandas de mercado", reformulando, assim, o papel dos assessores executivos em todos os lugares.

Segundo Sabino e Rocha (2004), torna-se imprescindível que o profissional de Secretariado Executivo saiba resolver diversos problemas e conflitos, pois ele é essencial no ramo executivo com os demais colaboradores de uma organização. Dessa forma, é necessário que esse trabalhador possua autocontrole das emoções, pois lida com o funcionamento geral da empresa, onde há exigências que envolvem a habilidade de se manter controlado e motivado para gerir o fluxo comunicacional.

Para esses profissionais, as adversidades são constantes, uma vez que convive em um ambiente que pode sofrer mudanças, de diversas naturezas, constantemente (Santos \& Correia, 2017). Além disso, se considera que ele necessita, por vezes, prestar assessoria para dois ou mais executivos, podendo, inclusive, gerenciar alguns setores e as pessoas que neles desenvolvem suas atividades, esse colaborador se tornará um possível mediador entre os setores da organização e o executivo.

Em face de tal cenário, é indispensável ao secretário executivo buscar o equilíbrio emocional. Em consonância com a necessidade dessa habilidade, Maurício e Lima (2017, p. 141) dizem que:

É fato, portanto, que as emoções interferem na conduta, no sentido de que podem auxiliar nas percepções e relações, sejam estas das mais concretas até àquelas mais abstratas. Assim, partindo-se dos pressupostos de que se deve aprender a lidar com as emoções de igual modo como se lida com os conhecimentos técnicos, nota-se, consequentemente, que a Inteligência Emocional contribui efetivamente no ambiente de trabalho, uma vez que estabelece os vínculos que tecem os relacionamentos, propiciando uma linha de conduta geral que pode resultar em desempenho eficaz.

Desse modo, compreende-se que o equilíbrio emocional adequado é determinado por mecanismos de análise e observação das diversas situações do dia a dia, já que cada resultado exige a adoção de diferentes meios de controle e atitudes. O hábito de controlar as emoções pode ser visto como uma ação importante, já que refletirá de forma direta em uma melhor qualidade de vida, tanto físico quanto mental.

No que diz respeito às características do profissional de secretariado executivo, é perceptível, no atual cenário, que a competividade e globalização se fazem presentes nos ambientes organizacionais. Com isso, entendese que é relevante para o campo do secretariado executivo fortalecer o desenvolvimento de suas habilidades laborais, de modo que seja possível ao profissional da área aperfeiçoar-se cada vez mais e isso se mostre um fator de contribuição para mantê-lo numa boa concorrência no mercado de trabalho (Silva, 2016).

Esses profissionais possuem o objetivo de realizarem elevados números de tarefas, e às frequentes mudanças e tendências que ocorrem no dia a dia secretarial (Santos \& Correia, 2017). Nesse sentido, a IE é útil, pois auxilia esses colaboradores a manterem uma postura considerada adequada (envolvendo a ética e a moral), 
com relação ao seu comportamento emocional, uma vez que a perda do controle das emoções, ainda que minimamente, pode resultar em consequências negativas tanto para organização, quanto para o profissional. Este podendo adquirir problemas psicológicos, inclusive (Gonçalves \& Cardim, 2018).

Em resumo, pode-se inferir que o secretário executivo possui diferentes papéis nas organizações (de técnico a assessor especializado) e sua atuação envolve as relações interpessoais que administra. Desse modo, a visão global da organização, a criatividade na relação personalizada com a clientela são aspectos que irão facilitar a convivência com fornecedores, clientes, colegas e o executivo, de tal forma que isso se torna uma realidade imprescindível no mundo atual (Neiva \& D’Elia, 2009). Naturalmente, também está em jogo a questão do uso da inteligência emocional no trabalho.

No tópico que segue, disserta-se sobre os aspectos metodológicos da pesquisa.

\section{Metodologia}

Para fins de direcionamento metodológico, neste estudo, adotam-se os agrupamentos de Santos (1999), quando este diz que as pesquisas podem ser classificadas quanto aos objetivos, quanto aos procedimentos de coleta e quanto às fontes de informação.

Nesse sentido, no tocante aos objetivos da pesquisa, o trabalho é descritivo. Sobre isso, Vergara (2000) argumenta que a pesquisa descritiva expõe as características de determinada população ou fenômeno, estabelece correlações entre variáveis e define sua natureza. Em outros termos, ela "não tem o compromisso de explicar os fenômenos que descreve, embora sirva de base para tal explicação" (Vergara, 2000, p. 47).

Enquanto estratégia de estudo, utilizou-se a perspectiva bibliográfica entendida como aquela que pode reunir contribuições culturais ou científicas realizadas no passado sobre um determinado assunto, tema ou problema que possa ser estudado (Lakatos \& Marconi, 2001; Cervo \& Bervian, 2002). No caso desta investigação, procura-se realizar uma revisão bibliográfica sobre a IE no âmbito do secretariado.

Sobre as fontes de informação, recorreu-se às bibliografias publicadas no campo secretarial, notadamente os artigos científicos das revistas, capítulos de livros e monografias. Embora houvesse o interesse em mapear as dissertações e teses produzidas sobre IE no secretariado, nenhum trabalho foi encontrado. No que diz respeito aos periódicos, quais sejam: Expectativa (e-ISSN 1982-3029), Secretariado Executivo em Revist@ (e-ISSN 18092802), Capital Científico (e-ISSN 2177-4153) e Revista de Gestão e Secretariado (e-ISSN 2178-9010). A escolha se deu pelo fato de que todos estão no WebQualis da Coordenação de Aperfeiçoamento de Pessoal de Nível Superior (Capes) e que são revistas com publicações recorrentes sobre o secretariado. No tocante ao recorte temporal, 2005-2019, o período teve a pretensão de apresentar o estado da arte para o tema "inteligência emocional no campo secretarial". Sabendo disso, o quadro a seguir contribui para se conhecer o universo da pesquisa nas revistas selecionadas.

Para elaboração da Figura 2, que será apresentado no tópico "Resultados e Discussões", realizou-se uma pesquisa nos sites das revistas investigadas, buscou-se pelo termo "inteligência emocional". Na Expectativa, foram encontrados 3 (três) artigos; na Secretariado Executivo em Revist@, 4 (quatro); na Capital Científico, 0 (zero); e na 
Revista de Gestão e Secretariado, 2 (dois). Vale lembrar que os resultados, para serem considerados neste estudo, deveriam ter relação com o secretariado.

Para ajudar nas análises, fez-se uma leitura de todos os trabalhos identificados, de modo que fosse possível identificar quais as possíveis contribuições dos estudos, numa perspectiva de mapeamento do estado da arte. Para, desse modo, tentar estabelecer relações com produções anteriores, identificar temáticas recorrentes, apontar novas perspectivas.

\section{Resultados e Discussões}

Nesta parte do trabalho, apresentam-se os achados, haja vista que o objetivo foi realizar uma revisão bibliográfica sobre a IE no âmbito do secretariado.

A Figura que segue traz informações sobre as produções científicas catalogadas, no que diz respeito aos artigos científicos.

Figura 2

Informações sobre os artigos catalogados

Artigos publicados em periódicos

$\begin{array}{lll}\text { Título Autores } & \text { Revista } & \text { Ano de publicação }\end{array}$

Secretária executiva nos processos de Luciana Alessio de Mello Secretariado Executivo em 2005
inteligência emocional Revist@

A ética e a inteligência emocional

Claudia Carla de Azevedo Secretariado Executivo em 2007 como pressupostos básicos para o Brunelli Rêgo Revist@ sucesso profissional do secretário executivo

A influência da inteligência emocional

Conceição de Maria

Expectativa 2010 no desempenho profissional de Pinheiro Barros, secretariado executivo Keiliany Moreira do Prado

A inteligência emocional como Luciana da Silva Palma, Secretariado Executivo em fator-chave para o desempenho Loiva Maria Vidal Revist@ do profissional de secretariado Medeiros executivo

Os tipos comportamentais dos executivos e a postura do

Rosane Fontanella Revista de Gestão e profissional de secretariado Gestão secretarial: a evolução das funções do profissional de secretariado e a efetividade da inteligência emocional nos processos de trabalho

Adriana Brun, Graziela Cechet, Susana Neumann
Secretariado

Secretariado Executivo em

2012 Revist@ 
Artigos publicados em periódicos

Título

Autores

Revista

Ano de publicação

Inteligência emocional: um diferencial

Elizomar Assis Nobre

Expectativa

2013

para o profissional de secretariado

executivo

Espiritualidade corporativa: realidade

Cibelle da Silva Santiago,

Revista de Gestão e

2014

ou mito na visão do profissional

Lidiane Reis, Maria

Secretariado

de secretariado?

Lizitana Conceição

dos Santos

A influência da inteligência emocional

Tirara Ferreira da Silva,

Expectativa

2019

no desempenho dos estagiários

de secretariado executivo da

Universidade Federal do Ceará

Joelma Soares Silva,

Thays Lyanny da

Cunha Garcia da

Rocha, Conceição de

Maria Pinheiro Barros

Nota. Elaborado pelos autores.

No conjunto de artigos publicados sobre IE, entre 2005 e 2019, notou-se certa tendência para pesquisar sobre a relação entre competência emocional e desempenho do profissional de secretariado, já que esse termo aparece nos títulos de cinco das nove obras identificadas: Mello (2005), Rêgo (2007), Barros e Prado (2010), Palma e Medeiros (2011) e Silva, Silva, Rocha, \& Barros. (2019).

Além disso, com base nas informações disponibilizadas nesses textos, foi possível constatar que três são classificados como bibliográficos e de campo, um bibliográfico, um teórico-bibliográfico e um de campo. Em Fontanella (2011), não há dados sobre a metodologia empregada no trabalho. Em síntese, parece necessário destacar que os estudos científicos, quase sempre, partem de bibliografias para se desenvolverem. Portanto, esperam-se outras informações metodológicas dos autores, além do que já parece ser óbvio.

Outros dois trabalhos, publicados em 2011 e 2014, tiveram propostas um tanto diferenciadas, como em Fontanella (2011), buscando mostrar como o profissional de secretariado consegue executar e administrar a sua função ao assessorar executivos com tipos comportamentais diferentes; ou em Santiago, Reis e Santos (2014), procurando identificar a existência ou não das práticas da espiritualidade corporativa numa fundação cultural, por meio da percepção do profissional de secretariado. Em ambos os casos, parece haver certa inovação temática para se conhecer outros elementos da relação entre IE e o campo secretarial.

Por fim, tem-se Brun, Cechet e Neumann (2012) que investigaram sobre a evolução das funções secretariais e a efetividade da inteligência emocional nos processos de trabalho, tratando-se, portanto, de uma revisão bibliográfica; e, ainda, Nobre (2013) que buscou demonstrar como as características emocionais podem ser coadjuvantes no processo de gestão secretarial, projetando os profissionais para atividades gerenciais, a agirem como agentes facilitadores da empresa ou instituição onde trabalham. No caso do artigo de Nobre (2013), notou-se 
que o foco é na relação da IE com as funções estratégicas do secretário executivo, o que pode ser visto como um olhar diferenciado para o problema de pesquisa.

No plano das contribuições para o secretariado, Barros e Prado (2010) conseguiram perceber que é importante para o profissional ser emocionalmente inteligente, tendo em vista que ele saberá utilizar as emoções a seu favor; Palma e Medeiros (2011) concluíram que o uso da inteligência emocional é essencial para o bom desempenho dos secretários executivos no âmbito empresarial e familiar, e que tais profissionais preferem organizações que estimulam o desenvolvimento dessa inteligência; já para Silva et al. (2019), o estudo permitiu revelar que os domínios da inteligência emocional possibilitam aos estudantes, como futuros secretários executivos, reconhecerem e lidarem com seus próprios sentimentos, gerenciar as emoções, compreender as emoções dos outros e construir uma rede de relacionamentos.

Fontanella (2011, p. 102) concluiu "que as pessoas são extremamente diferentes umas das outras, em sua forma de pensar, agir e interagir; porém essas diferenças são necessárias para o crescimento e desenvolvimento da empresa". Além disso, "vê-se a diversidade comportamental como algo positivo nas organizações, podendo esta enriquecer os trabalhos desenvolvidos, trazer benefícios às empresas [...]". Santiago, Reis e Santos (2014), por sua vez, chegaram à conclusão de que a espiritualidade corporativa ainda não é uma prática existente na instituição investigada.

Brun, Cechet e Neumann (2012, p. 49) chegaram à conclusão de que o estudo empreendido por essas autoras [...] se apresenta como uma contribuição para uma reflexão, com a possibilidade de abrir novas discussões sobre a gestão secretarial relacionada às transformações intelectuais e ao equilíbrio das emoções no exercício profissional do secretariado executivo nas organizações.

Nobre (2013, p. 18-19) destacou que "novos conhecimentos, habilidades e atitudes, requisitadas no ambiente corporativo, atualmente são importantes para um profissional no desempenho de suas funções". Ademais, que "esse equilíbrio é fundamental para alicerçar todas as demandas que um secretário executivo possui no seu dia a dia e que lhe será extremamente útil para gerir suas atividades, sua carreira e sua vida".

A seguir, tem-se as considerações sobre os capítulos de livro catalogados. 
Figura 3

Informações sobre os capítulos de livro

Capítulos de livro

Título

Autores

Livro

Ano de publicação

\begin{tabular}{|c|c|c|c|}
\hline $\begin{array}{l}\text { Inteligência emocional e social: a } \\
\text { resiliência em secretariado }\end{array}$ & $\begin{array}{l}\text { Cibele Martins, Luiz } \\
\text { Genghini }\end{array}$ & $\begin{array}{l}\text { Excelência no Secretariado: } \\
\text { a importância } \\
\text { da profissão nos } \\
\text { processos decisórios. } \\
\text { Como assessorar e } \\
\text { atingir resultados } \\
\text { corporativos e pessoais } \\
\text { com competência e } \\
\text { qualidade }\end{array}$ & 2013 \\
\hline $\begin{array}{l}\text { O conhecimento emocional do } \\
\text { secretário executivo a partir do } \\
\text { Aplicativo Core Quality }\end{array}$ & $\begin{array}{l}\text { Fernanda Maria Alves } \\
\text { Lourenço }\end{array}$ & $\begin{array}{l}\text { Modelos de Gestão } \\
\text { no Contexto do } \\
\text { Profissional de } \\
\text { Secretariado }\end{array}$ & 2015 \\
\hline $\begin{array}{l}\text { Inteligência emocional focada em } \\
\text { sala de aula }\end{array}$ & $\begin{array}{l}\text { Lu Paranhos, Solange } \\
\text { Costa }\end{array}$ & $\begin{array}{l}\text { O futuro do secretariado: } \\
\text { educação e } \\
\text { profissionalismo }\end{array}$ & 2019 \\
\hline
\end{tabular}

Nota. Elaborado pelos autores.

No grupo de capítulos de livro identificados, publicados entre 2013 e 2019, os temas se mostraram mais complexos, conforme seguem: em Martins e Genghini (2013), os autores dissertaram sobre a inteligência emocional e social como forma de resiliência para o secretariado; Lourenço (2015) buscou estabelecer uma relação do conhecimento emocional do secretário executivo com o Aplicativo Core Quality; por fim, Paranhos e Costa (2019) focaram na inteligência emocional para os docentes.

Martins e Genghini (2013) inferiram que a resiliência, enquanto "característica da inteligência emocional e social, é um diferencial imprescindível e indispensável ao desenvolvimento e competitividade do profissional, em especial, o de secretariado [...]". Já Lourenço (2015), concluiu que o secretário executivo, além das rotinas do dia a dia, "também precisa saber gerenciar suas emoções e particularidades, tendo em mente que estas são peçaschave para o seu bom desempenho profissional e pessoal, [...]". As autoras Paranhos e Costa (2019) entendem que ao reconhecer as emoções das pessoas ao seu redor, o professor estaria criando um canal fértil e acessível para a interação equilibrada. Os autores oferecem algumas dicas para a sala de aula, tais como: exercite a empatia, incentive o autoconhecimento, aponte o caminho, vença os "sabotadores" e seja proposital. 
Tendo concluída a apresentação dos artigos e dos capítulos de livro, segue-se com a mostra das monografias.

\section{Figura 4}

Informações sobre as monografias

\section{Monografias}

Título

Autores

Monografia de graduação

Ano de publicação

Avaliando o quociente de inteligência

Maíra Guimarães Ribeiro

Monografia

emocional do profissional de

secretariado no trabalho

A inteligência emocional e sua

Larissa Estherphane

Monografia

importância para a atuação dos

Cacho de Oliveira

profissionais de secretariado

executivo nas organizações

A inteligência emocional como

Sibelly Azevedo Silva

Monografia

facilitadora da gestão de

conflitos: visão dos estudantes de

secretariado executivo

A utilização da inteligência emocional

no ambiente de trabalho e

Dayane Carvalho de

Monografia

Sousa

sua importância para relações

interpessoais: estudo de caso dos

profissionais de secretariado da

Universidade Federal de Sergipe

A inteligência emocional e a resolução de conflitos interpessoais no

Nathalia Ingrid Simões

Monografia

Ramos

cotidiano do secretário executivo

Inteligência emocional e a atuação

Alyne Silva Dutra

Monografia

do secretário, uma análise dos

Shadia Ribeiro dos Santos

depoimentos dos acadêmicos e

egressos

Inteligência emocional e percepção

Allayne Tavares

Monografia

das atitudes e competências

do profissional no ambiente

corporativo

A inteligência emocional no ambiente de trabalho do secretário

Karla Thayany Souza

Monografia

executivo

Martins 
Monografias

\begin{tabular}{|c|c|c|c|}
\hline Título & Autores & Monografia de graduação & Ano de publicação \\
\hline $\begin{array}{l}\text { A influência da inteligência emocional } \\
\text { sobre o desempenho dos } \\
\text { estagiários acadêmicos de } \\
\text { secretariado executivo da } \\
\text { Universidade Federal do Ceará }\end{array}$ & Tiara Ferreira da Silva & Monografia & 2016 \\
\hline $\begin{array}{l}\text { Inteligência emocional e o } \\
\text { desenvolvimento das } \\
\text { competências do profissional de } \\
\text { Secretariado Executivo }\end{array}$ & $\begin{array}{l}\text { Josefa Hérsila de Oliveira } \\
\text { Fontes }\end{array}$ & Monografia & 2018 \\
\hline $\begin{array}{l}\text { Inteligência emocional e resultados } \\
\text { corporativos do profissional de } \\
\text { secretariado: um estudo de caso }\end{array}$ & Soleane Teixeira da França & Monografia & 2019 \\
\hline
\end{tabular}

Nota. Elaborado pelos autores.

No plano das monografias, identificou-se onze trabalhos, defendidos entre 2010 e 2019. Desse total, conseguiu-se ter acesso a apenas oito deles. Os três não encontrados na internet foram: 1) A inteligência emocional e sua importância para a atuação dos profissionais de secretariado executivo nas organizações (Oliveira, 2010); 2) A utilização da inteligência emocional no ambiente de trabalho e sua importância para relações interpessoais: estudo de caso dos profissionais de secretariado da Universidade Federal de Sergipe (Sousa, 2013); e 3) Inteligência emocional e percepção das atitudes e competências do profissional no ambiente corporativo (Tavares, 2014).

De modo geral, pelos títulos das monografias que se teve acesso, dois estão situados no plano da discussão sobre saber se a IE é algo importante ou não, como é o caso de Oliveira (2010) e Sousa (2013); outros dois procuram relacionar a IE com a gestão de conflitos: Silva (2010) e Ramos (2013); Tavares (2014) e Fontes (2018), por sua vez, enveredam sobre o universo das competências secretariais e o lugar da IE. Numa direção similar, Dutra e Santos (2013) e Martins (2016) objetivaram saber como ocorre a conexão entre IE e o ambiente de trabalho do secretário, ou seja, na prática da atuação; e, por fim, três estudos se mostram mais ou menos preocupados com os mesmos objetos, quais sejam: quociente de IE, influência da IE no desempenho secretarial e IE/resultados corporativos. São eles de autoria de Ribeiro (2010), Silva (2016) e França (2019).

Em Silva (2010) tem-se a constatação de que existe, por parte dos estudantes de secretariado executivo, a eficácia em gerenciar os conflitos à luz da inteligência emocional como forma de se favorecer o crescimento pessoal e organizacional. Já Ramos (2013) constatou que o uso da inteligência emocional é primordial para a resolução dos conflitos interpessoais na organização.

Fontes (2018) identificou que a IE representa fator fundamental para que o secretário executivo exerça com eficiência suas competências profissionais. Dutra e Santos (2014), por sua vez, concluíram que o uso da inteligência emocional é fundamental para a atuação do profissional em secretariado executivo, no âmbito organizacional; 
enquanto Martins (2016) identificou que os profissionais de secretariado reconhecem a relevância que a inteligência emocional possui no ambiente de trabalho e a utilização dos fatores que envolvem esta inteligência.

Por fim, Ribeiro (2010) descobriu que os profissionais de secretariado possuem, em sua maioria, um bom nível de inteligência emocional e todos eles preocupam-se em desenvolvê-la, tanto no ambiente de trabalho como na vida pessoal. Por sua vez, Silva (2016) constatou que os domínios da inteligência emocional possibilitam aos estudantes, como futuros secretários executivos, reconhecerem e lidarem com seus próprios sentimentos, gerenciar as emoções, compreender as emoções dos outros e construir uma rede de relacionamentos.

França (2019) aponta que a opção pelo uso da resiliência, frente às situações adversas, e o exercício da inteligência emocional na forma de silêncio e aceitação em empresa que não oferecem oportunidade de ascensão profissional, desembocam em uma não abertura para o diálogo e fluidez da comunicação, com vistas ao aprimoramento dos serviços executados no âmbito operacional.

De modo preliminar, é possível constatar que nos estudos de Ribeiro (2010), Silva (2010), Ramos (2013), Dutra e Santos (2014), Martins (2016) e Fontes (2018) há certa previsão para os resultados das pesquisas, pois os objetivos delas não eram complexos, logo, já se previam quais seriam os possíveis achados. No entanto, nas investigações das autoras Silva (2016) e França (2019) constatam-se resultados mais consistentes e interessantes do ponto de vista científico.

De acordo com os resultados obtidos, possuir uma saudável inteligência emocional é importante para o profissional de secretariado no âmbito do trabalho, já que auxilia na diminuição da carga de estresse, propicia um aumento na produtividade, promove uma boa relação entre esse profissional e seus colegas, superiores, clientes, fornecedores e um desempenho dentro e fora da organização. Para atingir estas metas, é fundamental que o secretário executivo faça uso da IE, adquirindo, exercitando e aplicando os componentes como: habilidades sociais, empatia, motivação, consciência autônoma e saber lidar com a emoção (Santos \& Correia, 2017; Gonçalves \& Cardim, 2018).

\section{Considerações Finais}

O mercado de trabalho para o profissional de secretariado tem se mostrado crescente e com novas formas de atuação. Naturalmente, demanda-se para o desenvolvimento de competências técnicas, comportamentais e até psicológicas, pois o espaço organizacional exige um controle na postura e no emocional, comportamentos considerados adequados frente às situações adversas.

Desse modo, este estudo teve como objetivo realizar uma revisão bibliográfica sobre a IE no âmbito do secretariado, destacando-se quais são as principais contribuições dos estudos científicos para a prática profissional do secretário executivo. Assim sendo, buscou-se responder à seguinte questão-problema: uma vez que os estudos sobre IE não são recentes e, aparentemente, já há uma quantidade significativa de trabalhos sobre o assunto no secretariado, quais têm sido as contribuições deixadas por essas pesquisas?

Além disso, foi possível catalogar vinte e três trabalhos relacionados à IE e o secretariado, sendo: nove artigos científicos, três capítulos de livro e onze monografias. Infelizmente, não se encontrou teses e dissertações 
sobre o tema no campo secretarial. No âmbito das contribuições, os artigos e os capítulos de livro se mostraram mais colaborativos do ponto de vista do objetivo da pesquisa/achados, o que não aconteceu com a maioria das monografias identificadas.

Este estudo representa um mapeamento inicial das pesquisas sobre o tema na área e, naturalmente, deixa incógnitas para estudos futuros, como refletir se é possível desenvolver pesquisas mais complexas relacionando IE e secretariado. Também, pensar se é possível avançar nas reflexões sobre a prática do secretariado e suas conexões com o uso da IE no espaço de trabalho. 


\section{Referências}

Alonso, M. E. C. (2002). A arte de assessorar executivos. São Paulo: Edições Pulsar.

Bar-On, R. (2006). The Bar-On model of emotional-social intelligence. Psicothema, 18, 13-25.

Bar-On, R. (2000). Emotional and social intelligence: Insights from the Emotional Quotient Inventory (EQ-i). En R. Bar-On, \& J. D. A. Parker (Eds.). Handbook of emotional intelligence: Theory, development, assessment and application at home, school and in the workplace (pp. 363-388). San Francisco, CA: Jossey-Bas.

Barros, C. M. P. \& Prado, K. M. (2010). A influência da inteligência emocional no desempenho profissional de secretariado executivo. Revista Expectativa, 9(1), 61-76. https://doi.org/10.48075/revex.v9i1.5871

Brun, A.; Cechet, G., \& Neumann, S. (2012). Gestão secretarial: a evolução das funções do profissional de secretariado e a efetividade da inteligência emocional nos processos de trabalho. Secretariado Executivo em Revist@, Passo fundo, 8(8), 36-51, 2012.

Cervo, A. L. \& Bervian, P. A. (2002). Metodologia científica, 5. ed. São Paulo: Prentice Hall.

Costa, F. J. (2014). Mensuração e desenvolvimento da inteligência emocional. Rio de Janeiro. Ciência moderna.

Dutra, A. S. (2014). Inteligência emocional e a atuação do secretário, uma análise dos depoimentos dos acadêmicos e egressos. Monografia (Tecnologia em Secretariado) - Universidade Federal do Paraná. Setor de Educação Profissional e Tecnológica.

Fulanetto, T. C. (2012). Inteligência emocional. Escola de Educação [S. I.]. Recuperado em 23 jul., 2020, de http// www.din.uem.br/ia/emocional/

Fonseca, L., Valle, T. M., Reis, R., \& Mesquita, K. (2016). Inteligência Emocional: uma competência da atualidade. In Congresso Nacional de Excelência em Gestão, 12., 2016, Rio de Janeiro. Rio de Janeiro: UFF. p. 1-23. Recuperado em 15 ago, 2019, de https://www.inovarse.org/sites/default/files/T16_216.pdf

Fontanella, R. (2012). Os tipos comportamentais dos executivos e a postura do profissional de secretariado. Revista de Gestão e Secretariado, 2(2), 79-104, maio.

Fontes, J. H. O. (2018). Inteligência emocional e o desenvolvimento das competências do profissional de Secretariado Executivo. Monografia (Bacharelado em Secretariado Executivo) - Departamento de Secretariado Executivo, Centro de Ciências Sociais Aplicadas, Universidade Federal de Sergipe, São Cristóvão.

França, S. T. (2019). Inteligência emocional e resultados corporativos do profissional de secretariado: um estudo de caso. Monografia (Graduação em Secretariado Executivo) - Departamento de Secretariado Executivo, Centro de Ciências Sociais Aplicadas, Universidade Federal de Sergipe, São Cristóvão.

Goleman, D. (1995). Inteligência Emocional: a teoria revolucionária que define o que é ser inteligente. Rio de Janeiro: Objetiva.

Goleman, D. (1998, 2001). Trabalhando com a Inteligência Emocional. Rio de Janeiro: Objetiva.

Goleman, D. (2007). Inteligência Emocional. Rio de Janeiro: Objetiva.

Gonçalves, R. P. \& Cardim, H. (2018). Gestão de Conflitos: a importância da inteligência emocional. São Paulo. SP. Lakatos, E. M. \& Marconi, M. A. (2001). Fundamentos metodologia científica, 4. ed. São Paulo: Atlas. 
Lauer, C. (2012). O que é inteligência emocional. Carreira \& Sucesso. [S. I.]. Recuperado em 23 jul., 2020, de http// www.catho.com.br/carreira-sucesso/dicas-emprego/o-que-e-inteligenciaemocional

Lourenço, F. M. A. (2015). O conhecimento emocional do Secretário Executivo a partir do Aplicativo Core Quality. In: Martins, C. B. \& D’elia, B. (Orgs.). Modelos de Gestão no Contexto do Profissional de Secretariado (pp. 91112). Florianópolis: Departamento de Ciências da Administração.

Lourenço, S. S. F. \& Lelis, M. G. (2019). A inteligência emocional no trabalho do secretário executivo. In Encontro Nacional Acadêmico de Secretariado Executivo, 6., Viçosa. Viçosa: UFV/ABPSEC, p. 1-16.

Martins, K. T. S. (2016). A inteligência emocional no ambiente de trabalho do secretário executivo. TCC (graduação em Secretariado Executivo) - Universidade Federal do Ceará, Faculdade de Economia, Administração, Atuária e Contabilidade, Fortaleza/CE.

Martins, C. B. \& Genghini, L. A. (2013). Inteligência emocional e social: A resiliência em Secretariado. In: D’Elia, B., Amorim, M., \& Sita, M. (Orgs.). Excelência no Secretariado: A importância da profissão nos processos decisórios. Como assessorar e atingir resultados corporativos e pessoais com competência e qualidade (pp. 241-249). São Paulo: Editora Ser Mais.

Maurício, F. \& Lima, T. (2017). Inteligência emocional: estudo acerca da atuação do profissional em Secretariado Executivo no ambiente organizacional. Revista Espaço Acadêmico, 16(191), 134-144.

Mayer, J. D. \& Salovey, P. (2007). ¿Qué es la inteligencia emocional? In J. M. M., Navas, \& P. F., Berrocal. (Coord.). Manual de inteligencia emocional (pp. 25-45). Madrid: Anaya.

Mello, L. (2005). Secretária executiva nos processos de inteligência emocional. Secretariado Executivo em Revist@, 1(1). Recuperado de http://seer.upf.br/index.php/ser/article/view/1732

Moreira, V. L. (2017). A importância da inteligência emocional nas organizações. Gestão e Desenvolvimento em Revista, 3(1).

Neiva, E. G. \& D’Elia, M. E. S. (2009). As novas competências do profissional de secretariado (2a ed.). São Paulo: IOB A. Thompson.

Nobre, E. A. (2013). Inteligência emocional: um diferencial para o profissional de secretariado executivo. Revista Expectativa, 12(1), 43-54, jul.

Nonato Junior, R. (2009). Epistemologia e teoria do conhecimento em secretariado executivo: a fundamentação das ciências da assessoria. Fortaleza: Expressão Gráfica.

Palma, L., \& Medeiros, L. M. (2012). A inteligência emocional como fator-chave para o desempenho do profissional de secretariado executivo. Secretariado Executivo Em Revist@, 7. Recuperado de http://seer.upf.br/index. php/ser/article/view/2327

Paranhos, L. \& Costa, S. (2019). Inteligência emocional focada em sala de aula. In: D’Elia, B. \& Almeida, W. (Orgs.). $O$ futuro do secretariado: educação e profissionalismo (pp. 39-46). São Paulo: Liretare Books. 
Pereira, M. S., Maciel, S. E. V., Clericuzi, A. Z., \& Deus, K. R. G. (2019). Gestão comportamental na profissão de secretariado executivo: um estudo na Universidade Federal da Paraíba, campi I e IV. Secretariado Executivo em Revist@, Passo Fundo, 15(1), 21-41, jan./jun.

Pereira, A. C. B., Macedo, E. V. S., Marques, G. A. S., Gomes, H. V., Paula, I. V. S. de, \& Martins, K. M. (2021). Inteligência emocional dentro da área de secretariado. TCC (Curso Técnico de Secretariado) - ETEC Lauro Gomes, São Bernardo do Campo-SP.

Ramos, N. I. S. (2013). A inteligência emocional e a resolução de conflitos interpessoais no cotidiano do secretário executivo. TCC (graduação em Secretariado Executivo) - Universidade Federal do Ceará, Faculdade de Economia, Administração, Atuária e Contabilidade, Fortaleza-CE.

Rêgo, C. C. de A. B. (2007). A ética e a inteligência emocional como pressupostos básicos para o sucesso profissional do secretário executivo. Secretariado Executivo em Revist@, 3(1). Recuperado de http://seer.upf.br/index. php/ser/article/view/1760

Ribeiro, M. G. (2010). Avaliando o quociente de inteligência emocional do profissional de secretariado no trabalho. Monografia (graduação em Secretariado Executivo) - Universidade Federal do Ceará, Faculdade de Economia, Administração, Atuária e Contabilidade, Fortaleza-CE.

Sabino, R. F. \& Rocha, F. G. (2004). Secretariado: do escriba ao web writer. Rio de Janeiro, Brasport.

Santos, A. R. (1999). Metodologia científica: a construção do conhecimento. Rio de Janeiro: DP \& A.

Santos, D. J. O. \& Correia, M. S. Gestão de mudanças: análise sobre a atuação do secretário executivo. In Simpósio Internacional de Gestão de Projetos, Inovação e Sustentabilidade, 6., São Paulo. São Paulo: Uninove, p. 1-16. Recuperado de http://www.singep.org.br/6singep/resultado/368.pdf

Santiago, C. S., Reis, L., \& Santos, M. L. C. (2014). Espiritualidade corporativa: realidade ou mito na visão do profissional de secretariado? Revista de Gestão e Secretariado, 5(3), 94-118, dez.

Silva, S. A. (2010). A inteligência emocional como facilitadora da gestão de conflitos: visão dos estudantes de secretariado executivo. Monografia (graduação em Secretariado Executivo) - Universidade Federal do Ceará, Faculdade de Economia, Administração, Atuária e Contabilidade, Fortaleza-CE.

Silva, T. F. (2016). A influência da inteligência emocional sobre o desempenho dos estagiários acadêmicos de secretariado executivo da Universidade Federal do Ceará. TCC (graduação em Secretariado Executivo) Universidade Federal do Ceará, Faculdade de Economia, Administração, Atuária e Contabilidade, Fortaleza/ CE.

Silva, T. F. da, Silva, J. S., Rocha, T. L. da C. G. da, \& Barros, C. de M. P. (2019). A influência da inteligência emocional no desempenho dos estagiários de secretariado executivo da Universidade Federal do Ceará. Revista Expectativa, 18(1), 99-126. https://doi.org/10.48075/revex.v18i1.18191

Sprea, J. (2009). Inteligência emocional: o diferencial nas organizações educacionais competitivas. Dissertação (Mestrado em Gestão de Empresas) - Instituto Superior de Ciências do Trabalho e da Empresa, LisboaPortugal. 
Vergara, S. C. (2000). Projetos e relatórios de pesquisa em administração, 3. ed. Rio de Janeiro: Atlas. 